\title{
8-Methoxy-naphtho[2,3-b]thiophen-4,9-quinone, a Non-competitive Inhibitor of Trypanothione Reductase
}

\author{
Carlos L Zani ${ }^{+}$, Alan H Fairlamb*
}

Laboratório de Química de Produtos Naturais, Centro de Pesquisas René Rachou-Fiocruz, Av. Augusto de Lima 1715, 30190-002

Belo Horizonte, MG, Brasil *Division of Biological Chemistry \& Molecular Microbiology, School of Life Sciences, The

Wellcome Trust Biocentre, University of Dundee, Dundee, UK

The enzyme trypanothione reductase is a recognised drug target in trypanosomatids and has been used in the search of new compounds with potential activity against diseases such as leishmaniasis, Chagas disease and African trypanosomiasis. 8-Methoxy-naphtho [2,3-b] thiophen-4,9-quinone was selected in a screening of natural and synthetic compounds using an in vitro assay with the recombinant enzyme from Trypanosoma cruzi. Its mode of inhibition fits a non-competitive model with respect to the substrate (trypanothione) and to the co-factor (NADPH), with Ki-values of 5 and $3.6 \mu \mathrm{M}$, respectively. When tested against human glutathione reductase, this compound did not display any significant inhibition at $100 \mu \mathrm{M}$, indicating a good selectivity against the parasite enzyme.

Key words: trypanothione reductase - Trypanosoma cruzi - Leishmania - enzyme inhibitors - naphthoquinone

Protozoa of the order Kinetoplastida occur in vast areas of tropical and subtropical regions of the world. Many of them are able to infect humans and cause diseases such as Chagas disease (American trypanosomiasis) caused by Trypanosoma cruzi, sleeping sickness (African trypanosomiasis) caused by Trypanosoma brucei gambiense or rhodesiense and leishmaniasis caused by various Leishmania spp. (http://www.who.int/tdr/diseases/default.htm). Current chemotherapeutic agents are either not effective for all stages of these diseases, present serious side effects or require a complicated administration regimen.

These parasites share a defence mechanism against oxidative stress based on the dithiol trypanothione $\left[N^{1}, N^{8}\right.$-bis(glutathionyl)-spermidine] and associated enzymes, specially trypanothione reductase (TR) (Fairlamb et al. 1985, Fairlamb \& Cerami 1992, Flohe et al. 1999). This enzyme was shown to be essential for these parasites survival and infectivity and is recognised as an important target for the development of new drugs against these diseases (Fairlamb 1999, Iribarne et al. 2002).

A lot of effort has been devoted to find TR inhibitors. Using either rational or empiric approaches, different classes of compounds, including peptides and peptoid, substituted polyamines, quinacrine and acridine analogues, 2-aminodiphenylsulfides, phenothiazine derivatives, substituted piperazines and nitrofuran derivatives, were studied for their inhibitory potential (see reviews by Werbovetz 2000, Augustyns et al. 2001, Schmidt \& KrauthSiegel 2002). Investigation of natural products, although

Sponsorship Fiocruz/CNPq/Pronex/The British Council/ Wellcome Trust

${ }^{+}$Corresponding author. Fax +55-31-3295.3115. E-mail: zani@cpqrr.fiocruz.br

Received 20 December 2002

Accepted 12 February 2003 not so extensive, disclosed interesting inhibitors such as ajoene from garlic (Gallwitz et al. 1999), bisbenzylisoquinoline alkaloids (Fournet et al. 1998, 2000), and polyamines such as lunarine (Bond et al. 1999) and kukoamine (Ponasik et al. 1995).

After the initial work of Henderson and co-workers (1988) naphthoquinone derivatives were further investigated for their action on TR (Jockers-Scherubl et al. 1989, Salmon-Chemin et al. 2000, 2001). In a previous work we reported the in vitro effect of several naphthothiophenquinone derivatives against epimastigote and trypomastigote forms of T. cruzi and the inhibition of the recombinant enzyme trypanothione reductase (Zani et al. 1997). We showed that quinone 8-Methoxy-naphtho[2,3b] thiophen-4,9-quinone (TNQ2) was able to inhibit the enzyme activity by $87 \%$ at $100 \mu \mathrm{M}$ after 30 min incubation. This compound was also one of the most active among 150 natural and synthetic compounds evaluated against TR (unpublished results). These findings stimulated us to carry out a more detailed investigation of the inhibition kinetics of this compound against TR and human glutathione reductase (hGR), the results of which are presented in this paper.

\section{MATERIALS AND METHODS}

8-Methoxy-naphtho[2,3-b]thiophen-4,9-quinone This compound was available from our previous work (Zani et al. 1997). Before use the material was recrystallized from $\mathrm{MeOH}-\mathrm{AcO}$ t to afford bright yellow needles with purity higher than $99.5 \%$, as determined by reversed phase HPLC. A $100 \mathrm{mM}$ stock solution was prepared in DMSO. This solution was diluted in the assay buffer to attain the desired concentrations in the assays.

In vitro assay with T. cruzi TR - Recombinant T. cruzi TR was obtained as described by Borges et al. (1995). Enzyme activity was determined spectrophotometrically at $340 \mathrm{~nm}$ in $40 \mathrm{mM}$ HEPES, $\mathrm{pH} 7.4$, containing $1 \mathrm{mM}$ EDTA, $200 \mu \mathrm{M}$ NADPH, and $20 \mathrm{nM}$ TR (assay volume 1 $\mathrm{ml}$ ). Enzyme was pre-incubated at $27^{\circ} \mathrm{C}$ with $100 \mu \mathrm{M}$ test compound for 5 min prior to addition of the substrate 
trypanothione disulphide $(50 \mu \mathrm{M})$. Control assays contained an equivalent amount of DMSO. The results were expressed as percent reduction in the trypanothione reductase activity.

In vitro assay with $h G R$ - hGR was purified from human erythrocytes (Worthington \& Rosemeyer 1974). Enzyme activity was determined under conditions similar to that used for TR, using hGR at $50 \mathrm{nM}$ and glutathione at $100 \mu \mathrm{M}$. The stock solution of TNQ2 was diluted in the assay buffer to attain the desired concentrations. Control assays contained an equivalent amount of DMSO. The results were expressed as percent reduction in the hGR activity.

Kinetic measurements - Initial enzyme velocities $\left(v_{0}\right)$ were measured using a Shimadzu UV-2401 spectrometer equipped with a sample changer and controlled by a PC running the kinetics software package. In experiments where the co-factor (NADPH) was the variable substrate, the substrates (trypanothione disulphide in the case of TR and glutathione disulphide in the case of hGR) were held constant at $100 \mu \mathrm{M}$. When the disulphide substrate was varied, NADPH was $200 \mu \mathrm{M}$. Kinetic parameters were obtained by non-linear fitting of $v_{0}$ against a range of substrate and inhibitor concentrations using GraFit software v.4.5.

\section{RESULTS AND DISCUSSION}

The naphthothiophenquinone TNQ2, available from our previous work (Zani et al. 1997), was re-crystallised from methanol-ethyl acetate to more than $99.5 \%$ purity, as assessed by HPLC analysis. A stock solution at $100 \mathrm{mM}$ was prepared in DMSO and appropriate dilutions were prepared in the assay buffer.

We initially checked that the incubation time of TNQ2 with TR does not affect its activity (data not shown) ensuring that the inhibition is not time dependent. Initial rates $\left(v_{0}\right)$ were then measured after 5 min incubation before the addition of the trypanothione with vigorous mixing. The decrease in the absorbance at $340 \mathrm{~nm}$ was measured and initial rates determined using the first $10-20 \mathrm{sec}$ of data, in such way that the correlation coefficient to a straight line was greater than 0.95 . Non-linear regression of the raw data was performed using GraFit to calculate the kinetic parameters $K_{m}$ and $K_{i}$ (Table). The graphical results are presented in Fig. 1 as Lineweaver-Burk plots, showing a clear simple linear non-competitive profile with respect to both NADPH and the substrate trypanothione.

TNQ2 was also tested on hGR, the enzyme with a similar function in the mammalian host. At $100 \mu \mathrm{M}$ the activity of this enzyme was reduced by only $15 \%$ (data not shown), indicating a much lower activity against the host enzyme and thus a good degree of selectivity.

In the case of a non-competitive inhibitor, the relative activity of TR can be calculated as follows:

$$
\frac{v_{i}}{v_{0}}=\frac{\frac{V_{\max }[S]}{\left(K_{m}+[S]\left(1+\frac{[I]}{K_{i}}\right)\right.}}{\frac{V_{\max }[S]}{K_{m}+[S]}}=\frac{K_{i}}{K_{i}+[I]}
$$

where $v_{\mathrm{i}}$ and $v_{0}$ are the inhibited and uninhibited rates for trypanothione reductase, respectively, $K_{m}$ is the Michaelis constant, $[S]$ and $[I]$ are concentrations of substrate and inhibitor, respectively and $K_{i}$ the inhibitor constant. When $v_{\mathrm{i}} / v_{0}=0.1$, it can be seen by rearranging the above equation that the concentration of inhibitor required for $90 \%$ inhibition $\left(\left[I_{90}\right)\right.$ is equal to $9 K_{i}$. Similar equations can be derived for competitive and uncompetitive inhibition (see Fig. 2). Since intracellular levels of reduced trypanothione are $\sim 1 \mathrm{mM}$ in $T$. cruzi (Ariyanayagam \& Fairlamb 1997) the behaviour of these types of reversible inhibitor is presented as a function of substrate concentration up to $0.5 \mathrm{mM}$ trypanothione disulphide. Note that, unlike competitive and uncompetitive inhibition, the $\left[I_{90}\right.$ for non-competitive inhibition is independent of the substrate concentration. Thus, even though trypanothione disulphide levels would be expected to increase in cells due to the metabolic roles of trypanothione as an antioxidant and as an electron donor for reduction of ribonucleotides, the level of inhibition of trypanothione reductase would remain constant.

TABLE

Inhibition of trypanothione reductase by TNQ2

\begin{tabular}{llll}
\hline & & \\
\hline $\begin{array}{l}\text { Variable substrate } \\
\begin{array}{l}\text { Nrypanothione } \\
\text { disulphide }\end{array}\end{array}$ & $K_{m}, \mu \mathrm{M}$ & $K_{i}, \mu \mathrm{M}$ & Inhibition type \\
\hline
\end{tabular}

Data from our previous work (Zani et al. 1997) shows that TNQ2 inhibited growth of epimastigotes with an $\mathrm{IC}_{50}$ of $14.3 \mu \mathrm{M}$. Assuming TNQ2 equilibrates across the membrane of the parasite, then, for $[I]=14.3 \mu \mathrm{M}$ (50\% inhibition of growth) and the $K_{i}$ values given in the Table, TR would be inhibited by about $75 \%$. In studies on conditional knockouts of trypanothione reductase in T. brucei, it was noted that growth completely ceased when enzyme levels fell to $95 \%$ of normal, but that lysis occurred only at even lower levels (Krieger et al. 2000). Also, in L. donovani expressing a dominant-negative mutant form of trypanothione reductase, growth was unaffected by up to $85 \%$ reduction in activity, although sensitivity to oxidant stress was increased (Tovar et al. 1998). T. cruzi epimastigotes would appear to be slightly more sensitive than these organisms, bearing in mind the assumption made above about the intracellular levels of TNQ2 and assuming TNQ2 does not affect other cellular processes. This compound was only partially effective $(27 \pm 7 \%$ lysis) against the trypomastigote form of $T$. cruzi in blood at much higher concentrations $(200 \mu \mathrm{M})$. This discrepancy could be due to factors such as: (a) the greatly re- 

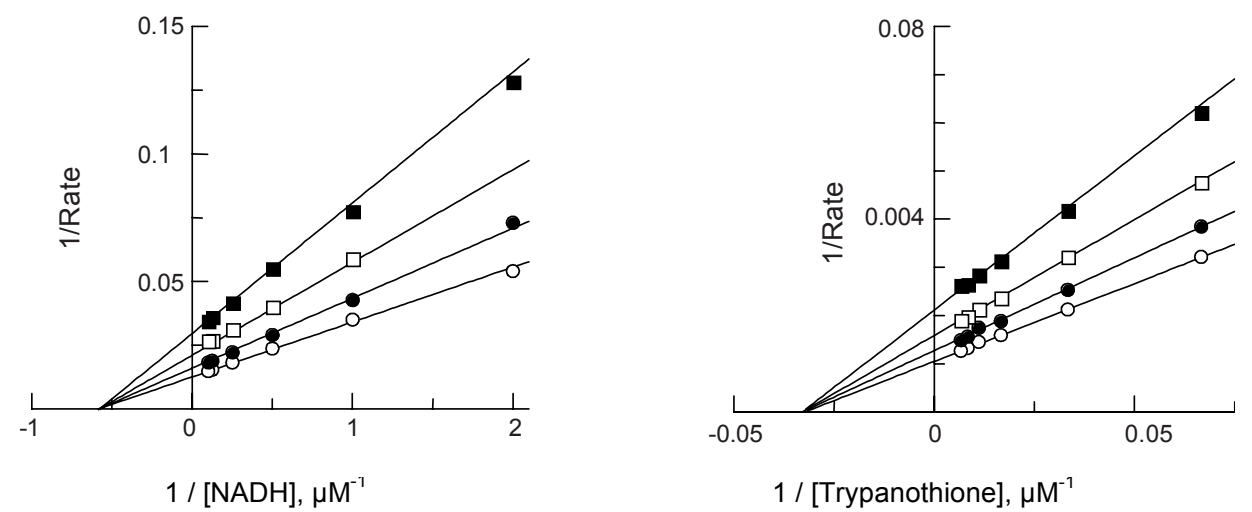

Fig. 1: lineweaver-Burk plots showing the simple linear non-competitive inhibition of trypanothione reductase by TNQ2 either to NADPH (left, [trypanothione] constant at $100 \mu \mathrm{M}$ ) and trypanothione (right, [NADPH] constant at $200 \mu \mathrm{M}$ ); open circles, [TNQ2] = 0 ; closed circles, [TNQ2] $=1 \mu \mathrm{M}$; open squares, [TNQ2] $=2.5 \mu \mathrm{M}$; and closed squares, [TNQ2] $=5 \mu \mathrm{M}$

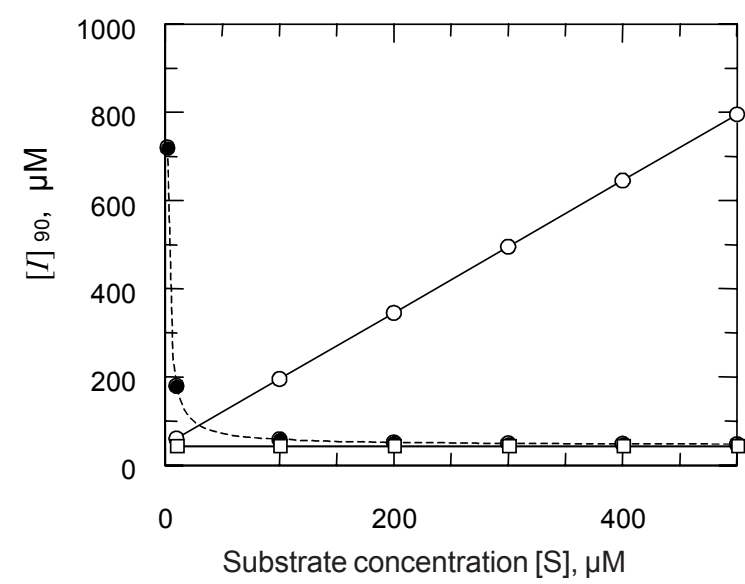

Competitive (binds to $\mathrm{E}$ form)

$$
[I]_{90}=9\left(1+\frac{[S]}{K_{m}}\right) K_{i}
$$

Uncompetitive (binds to ES form)

$$
[I]_{90}=9\left(1+\frac{K_{m}}{[S]}\right) K_{i}
$$

Mixed / non competitive (binds to $\mathrm{E}$ and $\mathrm{ES}$ forms) $[I]_{90}=9 K_{i}$

Substrate concentration [S], $\mu \mathrm{M}$

Fig. 2: inhibitor concentration required for $90 \%$ inhibition as a function of substrate concentration for different types of reversible inhibitor. Data are calculated for $K_{m}=30 \mu \mathrm{M}$ and $K_{i}=5 \mu \mathrm{M}$; open circles, competitive; closed circles, uncompetitive; and open squares, mixed/non competitive

duced metabolic activity of $T$. cruzi at $4{ }^{\circ} \mathrm{C}$ retarding the trypanocidal effect, (b) the reduced requirement for ribonucleotide reduction in non-dividing trypomastigote stages or (c) the difference in end point measurement (i.e. growth versus lysis). Since the most striking difference in the properties of TR and hGR is at their respective disulphide-binding sites, most compounds have been designed as competitive inhibitors. As discussed above, such inhibitors suffer from the disadvantage that their inhibitory effects are reversed by the accumulation of trypanothione disulphide. Irreversible inhibitors such as the antimonial drugs (Cunningham \& Fairlamb 1995) or lunarine (Bond et al. 1999) or its analogues (Hamilton et al. 2003), or non-competitive inhibitors such as TNQ2 may offer a more fruitful approach. Work is in progress to identify the binding site for TNQ2 in order to increase potency and selectivity of this interesting lead.

\section{ACKNOWLEDGMENTS}

To Mr Ahilan Saravanamuthu for preparation of trypanothione reductase used in these studies. CLZ acknowledges the British Council-Fiocruz for a Travelling Fellowship to visit the UK. AHF is supported by the Wellcome Trust.

\section{REFERENCES}

Ariyanayagam MR, Fairlamb AH 1997. Diamine auxotrophy may be a universal feature of Trypanosoma cruzi epimastigotes. Mol Biochem Parasitol 84: 111-121.

Augustyns K, Amssoms K, Yamani A, Rajan, P K, Haemers A 2001. Trypanothione as a target in the design of antitrypanosomal and antileishmanial agents. Curr Pharm Des 7: 1117-1141.

Bond CS, Zhang Y, Berriman M, Cunningham ML, Fairlamb AH, Hunter WN 1999. Crystal structure of Trypanosoma cruzi trypanothione reductase in complex with trypanothione, and the structure-based discovery of new natural product inhibitors. Structure Fold Des 7: 81-89.

Borges A, Cunningham ML, Tovar J, Fairlamb AH 1995. Sitedirected mutagenesis of the redox-active cysteines of Trypanosoma cruzi trypanothione reductase. Eur J Biochem 228: 745-752.

Cunningham ML, Fairlamb AH 1995. Trypanothione reductase from Leishmania donovani. Purification, characterisation and inhibition by trivalent antimonials. Eur $J$ 
Biochem 230: 460-468.

Fairlamb AH 1999. Future prospects for the chemotherapy of Chagas' disease. Medicina (B Aires) 59: 179-187.

Fairlamb AH, Cerami A 1992. Metabolism and functions of trypanothione in the Kinetoplastida. Annu Rev Microbiol 46: 695-729.

Fairlamb AH, Blackburn P, Ulrich P, Chait BT, Cerami A 1985. Trypanothione: a novel bis(glutathionyl)spermidine cofactor for glutathione reductase in trypanosomatids. Science 227: $1485-1487$

Flohe L, Hecht HJ, Steinert P 1999. Glutathione and trypanothione in parasitic hydroperoxide metabolism. Free Radic Biol Med 27: 966-984.

Fournet A, Inchausti A, Yaluff G, Rojas De Arias A, Guinaudeau H, Bruneton J, Breidenbach MA, Karplus PA, Faerman CH 1998. Trypanocidal bisbenzylisoquinoline alkaloids are inhibitors of trypanothione reductase. J Enzyme Inhib 13: 1-9.

Fournet A, Rojas de Arias A, Ferreira ME, Nakayama H, Torres de Ortiz S, Schinini A, Samudio M, Vera de Bilbao N, Lavault M, Bonte F 2000. Efficacy of the bisbenzylisoquinoline alkaloids in acute and chronic Trypanosoma cruzi murine model. Int J Antimicrob Agents 13: 189-195.

Gallwitz H, Bonse S, Martinez-Cruz A, Schlichting I, Schumacher K, Krauth-Siegel RL 1999. Ajoene is an inhibitor and subversive substrate of human glutathione reductase and Trypanosoma cruzi trypanothione reductase: crystallographic, kinetic, and spectroscopic studies. JMed Chem 42: 364-372.

Hamilton CJ, Saravanamuthu A, Eggleston IM, Fairlamb AH 2003. Ellman's reagent-mediated regeneration of trypanothione in situ: Substrate economic microplate and timedependent inhibition assays for trypanothione reductase. Biochem J 369: 529-537.

Henderson GB, Ulrich P, Fairlamb AH, Rosenberg I, Pereira M, Sela M, Cerami A 1988. "Subversive" substrates for the enzyme trypanothione disulfide reductase: alternative approach to chemotherapy of Chagas disease. Proc Natl Acad Sci USA 85: 5374-5378.

Iribarne F, Paulino M, Aguilera S, Murphy M, Tapia O 2002. Docking and molecular dynamics studies at trypanothione reductase and glutathione reductase active sites. JMol Model (Online) 8: 173-183.

Jockers-Scherubl MC, Schirmer RH, Krauth-Siegel RL 1989.
Trypanothione reductase from Trypanosoma cruzi. Catalytic properties of the enzyme and inhibition studies with trypanocidal compounds. Eur J Biochem 180: 267-272.

Krieger S, Schwarz W, Ariyanayagam MR, Fairlamb AH, Krauth-Siegel RL, Clayton C 2000. Trypanosomes lacking trypanothione reductase are avirulent and show increased sensitivity to oxidative stress. Mol Microbiol 35: 542-552.

Ponasik JA, Strickland C, Faerman C, Savvides S, Karplus PA, Ganem B 1995. Kukoamine A and other hydrophobic acylpolyamines: potent and selective inhibitors of Crithidia fasciculata trypanothione reductase. Biochem J 311: 371375.

Salmon-Chemin L, Buisine E, Yardley V, Kohler S, Debreu MA, Landry V, Sergheraert C, Croft SL, Krauth-Siegel RL, Davioud-Charvet E 2001. 2- and 3-substituted 1,4-naphthoquinone derivatives as subversive substrates of trypanothione reductase and lipoamide dehydrogenase from Trypanosoma cruzi: synthesis and correlation between redox cycling activities and in vitro cytotoxicity. $J \mathrm{Med}$ Chem 44: 548-565.

Salmon-Chemin L, Lemaire A, De Freitas S, Deprez B, Sergheraert C, Davioud-Charvet E 2000. Parallel synthesis of a library of 1,4-naphthoquinones and automated screening of potential inhibitors of trypanothione reductase from Trypanosoma cruzi. Bioorg Med Chem Lett 10: 631-635.

Schmidt A, Krauth-Siegel RL 2002. Enzymes of the trypanothione metabolism as targets for antitrypanosomal drug development. Curr Top Med Chem 2: 1239-1259.

Tovar J, Cunningham ML, Smith AC, Croft SL and Fairlamb AH 1998. Down-regulation of Leishmania donovani trypanothione reductase by heterologous expression of a transdominant mutant homologue: effect on parasite intracellular survival. Proc Natl Acad Sci USA 95: 53115316

Werbovetz KA 2000. Target-based drug discovery for malaria, leishmaniasis, and trypanosomiasis. Curr Med Chem 7: 835-860.

Worthington DJ, Rosemeyer MA 1974. Human glutathione reductase: purification of the crystalline enzyme from erythrocytes. Eur J Biochem 48: 167-177.

Zani CL, Chiari E, Krettli AU, Murta SM, Cunningham ML, Fairlamb AH, Romanha AJ 1997. Anti-plasmodial and antitrypanosomal activity of synthetic naphtho[2,3-b]thiopen4,9-quinones. Bioorg Med Chem 5: 2185-2192. 